\title{
La narrativa distópica como lectura imprescindible del lector crítico en la sociedad actual. El caso de The Giver. EI Dador de Recuerdos'
}

\author{
Dystopian Narrative as Essential Reading for Critical Readers \\ in Nowadays Society. The example of Lois Lowry's The Givers
}

\author{
AMANDO LÓPEZ VALERO \\ Universidad de Murcia \\ ISABEL JEREZ MARTÍNEZ \\ Universidad de Castilla-La Mancha \\ España \\ amandolo@um.es \\ isabel.jerezmartinez@uclm.es
}

(Recibido IO-O2-20I3; aceptado I9-O9-2OI3)

Resumen. En esta aportación tratamos de justificar por qué existe la necesidad de formar lectores críticos en la sociedad dinámica y cambiante del siglo XXI. Considerando que las obras distópicas contribuyen a la conformación de dicha tipología de lector, en este ensayo analizaremos como texto principal The Giver. El Dador de recuerdos de Lois Lowry, tratando de mostrar las ideas principales que la ficción representa en la citada obra. También la contrastaremos con otras obras de características similares escritas con anterioridad a la misma. Uno de los planteamientos principales es comprobar si los valores desplegados en el libro tienen en la actualidad algún reflejo en nuestra sociedad, demostrando de ese modo la vigencia de la obra.

Palabras clave: Literatura; lectores; valores; educación.
Abstract. In this contribution we aim to justify the need for training critical readers within the framework of the dynamic society of the 2 Ist century. Assuming that dystopian works help to design the conformation of this kind of reader, in this text we will try to analyze The Giver by Lois Lowry as main work. Through this paper we will show the main fictional ideas included in Lowry's book, comparing it to the different works which preceded it in time. One of the main ideas of the paper is to know whether the values included in the book are still valid in our society, showing the book's strength in that way.

Key words: Literature; readers; values; education.

\footnotetext{
${ }^{\text {I }}$ Para citar este artículo: López Valero, Amando y Jerez Martínez, Isabel (2OI3). La narratiya distópica como lectura imprescindible del lector crítico en la sociedad actual. El caso de The Giver. ElDador de Recuerdos. Alabe 8. [www.revistaalabe.com]
} 


\section{I- Introducción}

Nuestro propósito es analizar el texto de Lois Lowry The Giver. El Dador de recuerdos. Trataremos por tanto en estas líneas de mostrar las ideas que la ficción representa en esta obra publicada en I993 y contrastarla con otras obras de características similares escritas con anterioridad a la misma. Una de las cuestiones que nos planteamos es comprobar si los valores desplegados en el libro tienen en la actualidad algún reflejo en nuestra sociedad.

El texto deja entrever la influencia de novelas distópicas como Un Mundo Feliz (Huxley), 1984 (Orwell) o Fahrenheit 45` (Bradbury). Estos textos surgen en diferentes épocas y representan inquietudes de las mismas o de ciertos sujetos de estas épocas a la luz de los acontecimientos que las vieron nacer.

La lectura del texto de Lowry muestra al lector joven modelos de comunidad y dentro de la misma, un determinado modelo familiar. Consideramos interesante observar las normas presentadas en la obra ya que son las que rigen los designios de esa comunidad y las que se proponen como óptimas para el funcionamiento social, por ello, trataremos de mostrarlas para, de este modo, poder contrastar si hay reflejo de ellas en la realidad actual o por el contrario quedan aisladas en la ficción. Si el lector joven encontrara atisbos de los modelos presentados en la ficción, puesto que trabajamos con distopías, la reflexión final será si realmente es interesante presentar este tipo de narrativa al receptor adolescente dado que le permitiría (si la lectura es crítica y por tanto, positiva) construir o reformular (si lo quisiera finalmente) sus estructuras cercanas de forma auténtica (familia, por ejemplo) conociendo y analizando pros y contras en su totalidad, siendo por ende, más libre y más consciente en su elección al haber realizado una visión profunda de los extremos (que la distopía muestra). Es decir, ¿pueden serle de ayuda al lector joven estas herramientas literarias para armonizar términos y no caer en posturas extremas en su vida?, ¿tendría entonces una función social constructiva la literatura distópica?

En estas páginas intentaremos responder a otras dos cuestiones subyacentes: si realmente puede darnos información del individuo (inmerso en una familia-educaciónsociedad) la literatura, o la ficción sólo es imaginación al servicio de la mente. Para tratar de tender puentes entre las ideas de los sujetos (inmersos en una determinada sociedad) y sus modos de representarlas (en este caso la Literatura Juvenil) hemos recurrido al método Hegeliano, la dialéctica y sus tres momentos: unidad simple, escisión u oposición y reconciliación, donde la filosofía una vez más, se alía con la literatura.

\section{2- Lectura crítica para la reflexión autónoma}

Un viejo proverbio dice: sicaen en tus manos oro y libros, recoge primero los libros y después el oro.

Leer es una actividad fundamental e imprescindible en nuestra sociedad dado que 
los textos escritos tienen una enorme repercusión en las actuales formas culturales (Tecnologías de la Información y Comunicación). Leer y escribir son acciones complejas que requieren mucho más que saber decodificar un texto. El buen lector, lo que en adelante llamaremos lector crítico, será competente y polivalente porque dominará diferentes formas de lectura, asimilará distintos tipos de texto y manejará diversos soportes. Desarrollará su actividad lectora movido por diferentes estímulos y lo hará en distintos contextos y situaciones. Buscará información para decidir, para transformarla en conocimiento, para tener juicios fundados sobre la realidad, para disfrutar. El lector crítico lee comprensivamente y sabe interpretar lo que lee, reformula, transforma contenidos. Por lo dicho, y coincidiendo con José Antonio Millán (2OOI) en su ensayo La lectura y la sociedad del conocimiento, la lectura es la llave del conocimiento en la sociedad de la información.

Leer es, por tanto, esencial para la evolución de los individuos, pero, ¿en qué consiste exactamente el acto de la lectura? Grosso modo podemos afirmar que la lectura constaría de cuatro fases siendo la primera la decodificación del signo gráfico donde logramos tender un puente entre grafema y sonido. El lector identifica los signos impresos, reconoce las palabras. Esta fase es esencial pero no suficiente ya que necesitamos que haya por parte del lector una comprensión, que supondría la segunda fase de los estadios de la lectura. En la fase comprensiva se produce la interpretación del sentido de los signos y es importante anotar que existen tres niveles de comprensión: el literal, el inferencial y el crítico. En el primer nivel (Reading on the lines) captaríamos el sentido explícito del texto, en el segundo nivel (reading between the lines) aprehenderíamos el sentido implícito del texto, reconociendo intenciones y propósitos del autor. Por último, el nivel crítico (reading beyond the lines) supondría un juicio personal sobre las ideas expresadas y una deducción de consecuencias. La lectura de un texto beyond the lines implica una comprensión crítica donde el lector recapacita sobre el sentido último del mensaje dándole un sentido único, aceptándolo o rehusándolo según ideas propias. En este punto, la información deja de serlo para el receptor y se transforma en conocimiento.

La tercera fase del proceso sería la de evaluación, en donde el lector ha asentado ciertos principios que han de servirle para el enjuiciamiento de lo leído y para la modificación de su pensamiento y actuación ante las ideas mostradas por el autor, es decir, reaccionaría ante lo leído. Además, sería capaz de apreciar el valor estético del texto (Quintero Gallego, 1987).

Concluiríamos esta escalera hacia la lectura total con una última fase, la de aplicación. Ésta consistiría en lograr integrar los aprendizajes de esa o esas lecturas en el sujeto receptor para que pueda llevar ese conocimiento a su vida (la educación para la vida de la que habla Delors, 1996), es decir, cuando el lector es capaz de utilizar lo leído en circunstancias específicas e individuales. Porque, a fin de cuentas, la lectura sirve al individuo para conocerse, para entender el mundo, para empatizar con los otros hombres y sus culturas, para dar explicación a todas las dudas de todos los hombres de todos los tiempos y otorgar cierta información que será transformada en conocimiento útil una vez concluidos los estadios de lectura. 
Este proceso puede ser considerado como un proceso alquímico, de transformación, donde vamos de la decodificación a la aplicación, de la información al conocimiento, de los símbolos ininteligibles al sentido último de todo signo. Quizá por eso, no yerra el dicho antiguo al afirmar: "recoge primero los libros y después el oro".

La reflexión y el cuestionamiento autónomo de aquello que se lee es necesario para todos los textos pero quizá lo sea más para aquellos que exploran la doble naturaleza del ser, para aquellos textos que muestran los extremos, las ideas llevadas a las últimas consecuencias donde quizá el hombre pierde su humanidad. Los extremos siempre son lo mismo (como muestra Alan Moore en su cómic V de Vendetta, capítulos tres y cuatro)

Los sueños pueden transformarse en pesadillas, eso muestra la narrativa distópica (J.S Mill) que hemos seleccionado en estas páginas, siendo The giver un extremo cacotópico (en terminología de Bentham) y donde esas fases de lectura total se muestran imprescindibles y necesarias (por útiles para no caer en el embrutecimiento y la resignación, que dirá el escritor) para las mentes inquietas que buscamos conocimiento (también) en los libros, como reflejo de lo real o para esclarecer la realidad que puede, en ocasiones, resultar opaca y críptica, como las pesadillas.

-¡No, no! -le atajó la Reina-. ¡La sentencia primero! ¡Tiempo habrá para el veredicto!

-¡Qué insensatez! -Exclamó Alicia-. ¿Dónde se ha visto que la sentencia se dicte antes de saber el veredicto?

-¡A callar! -Vociferó la Reina, poniéndose roja de ira.

-¡No me da la gana! -le contestó Alicia.

- ¿Que le corten la cabeza! -chilló la Reina con toda la fuerza de sus pulmones. Pero nadie se movió.

-¡Ya nadie te hace caso! -dijo Alicia, que había recobrado su tamaño habitual-. ¿Cómo te van a hacer caso si no son más que un mazo de cartas?

Al oír esto, la baraja entera se elevó por los aires y las cartas comenzaron a caer sobre el rostro de Alicia... Hasta que despertó, tumbada en la orilla del río. (Carroll, 2003: 227)

\section{3-Estructuras, valores sociales y fomento de la lectura}

Una vez trazados los límites del lector crítico, capaz de cuestionar y relacionar la información transformándola en conocimiento y capaz a su vez de aplicar el mismo en su vida cotidiana, vamos a avanzar en las estructuras inmediatas que rodean a ese lector, las estructuras que posibilitarán que los jóvenes logren crecer y desarrollar sus capacidades y habilidades lectoras, estructuras que favorecerán la lectura de historias sobre la historia de la humanidad para la preservación y evolución de la misma.

Sociedad, escuela, familia, individuo... y viceversa, esta será la espiral que trataremos de mostrar dado que la macro-estructura se sostiene por la micro-estructura y a la inversa, se retroalimentan y apoyan para el funcionamiento del sistema total y por tanto del avance común. 
Si aceptamos esta formulación de muñecas rusas vemos que todo es lo mismo y representa lo mismo y que desde lo más pequeño (micro-mundo individual de los sujetos) hasta lo más grande (sociedades) son la misma "cosa". Y ¿qué podría ser "la cosa humana”, también conocida como humanidad? Pues quizá sistemas de ideas-valores-creencias que se representan o muestran en sus signos. Por eso, si analizamos los signos encontraremos respuestas a la pregunta, o más preguntas, lo que indicará que somos personas críticas y lectores ávidos, por tanto humanos haciendo uso de sus capacidades únicas.

Si consideramos estas palabras, entonces podemos poner el acento en una de estas partes para comprender el todo. En estas páginas nos hemos centrado en la familia para comprender el resto de estructuras (de muñeca rusa) y lo hemos hecho a través del estudio que Lowry (ficción) muestra en su obra The Giver, El dador de recuerdos.

Este libro puede encontrarse en librerías o bibliotecas, en estanterías de adolescentes y jóvenes, (incluso en la red podemos encontrar un juego que nos ayudará a comprender a los personajes y fomentar la lectura inteligente del texto), pero ¿̈realmente puede darnos información del individuo (inmerso en una familia-educación-sociedad) la literatura, el Arte? ¿O la ficción sólo es eso, imaginación al servicio de la mente?

\section{4-Sistema de representación de ideas. De Hegel a Lowry}

Hegel, con su dialéctica intenta conocer la realidad en sí misma, para ello concibe la razón como el instrumento que es capaz de abarcarlo todo (lo finito y lo absoluto) y conocer la totalidad de lo real. La parte sólo puede ser explicada en función de la totalidad y la realidad total es historia, y no se puede desgajar un ser de la historia porque cada ser está dentro del devenir del todo (Heráclito), es un momento del proceso.

El conocimiento no puede entender una cosa particular sino dentro del Todo. La realidad no es estática sino movimiento, oposición, conflicto que poco a poco se va reduciendo al equilibrio. Cada cosa concreta remite a la totalidad, por eso el motor de ese devenir es el desajuste propio de la relación con el todo. La realidad es por tanto, según Hegel, dialéctica, que se mueve por la contradicción entre lo que es y lo que tiene que llegar a ser para "ajustarse" al Todo.

Las ideas se manifiestan en tríadas dialécticas: la idea en sí, la idea fuera de sí y la idea para sí. Es en esta última (idea para sí), donde encontramos la Filosofía del Espíritu (como suprema realidad) que a su vez se divide en Espíritu subjetivo, objetivo y absoluto. Dentro del espíritu absoluto encontramos el arte como manifestación de la idea para sí, que es la conciencia del hombre que conoce y se conoce, donde el sujeto se encuentra consigo mismo en el Arte (literatura en este caso). Por tanto podríamos afirmar que las ideas se manifiestan y son síntesis de luchas de contrarios en el arte, o que el arte nos dará una información de la realidad dado que es el espacio donde el sujeto reflexiona (superados objetivismo y subjetivismo) y llega a la totalidad (o absoluto) sobre sus ideas, que son muestras de la realidad misma que ayudan a la humanidad a conocer. 
"Del ser-ahí efectivamente real del hombre forma parte el mundo circundante”... “pues el ideal es la idea identificada con su realidad” (Hegel, 2007: I78)

Desde la antigüedad, cada pensador se propone resolver el "problema” del mundo, dar un paso más para su aprehensión. Esta visión de análisis que muestra Hegel es una de tantas formas de aproximarnos al conocimiento generando preguntas, armonizando términos para poder vislumbrar ideas reflejadas en el arte como medio de manifestación y representación.

¿Qué ideas aparecen representadas en El dador de recuerdos?, ¿por qué?, ¿cuál es su visión de la familia, como parte de la muñeca rusa que es idéntica al todo, o sociedad?, ¿hay vínculos, por tanto, entre la realidad y la ficción?, ¿es interesante entonces su lectura?, ¿por qué tipo de lector?, ¿todos podemos leerlo?, ¿serviría para el avance de la sociedad o es una trampa para el mismo?

Veamos a continuación, y sin más preámbulo necesario, el sistema de ideas representadas en la novela distópica que analizamos mostrándola primero junto a otras obras anteriores de características similares y analizando aspectos que van de la micro a la macro-estructura.

\section{5 -Ideas representadas que se repiten en el espacio y en el tiempo: Huxley, Bradbury, Orwell, Lowry}

Podemos afirmar que hay aspectos que se repiten como leit motiv en las cuatro novelas. En relación a la primera estructura, la familia, observamos que en las representaciones de ideas en el tiempo o bien se suprime la familia para aislar al individuo o bien participa de la norma o control de la macroestructura, sustentándola desde el grupo-base que supone el seno familiar.

La televisión en la obra Fahrenheit $45^{\prime}$ es un miembro más junto a Montag y Mildred, otro miembro aséptico y frío. "El televisor es real. Es inmediato, tiene dimensión. Te dice lo que debes pensar y te lo dice a gritos. Ha de tener razón. Parece tenerla. Te hostiga tan apremiantemente para que aceptes que tu mente no tiene tiempo para protestar, para gritar: ¡Qué tontería!”

En la obra 1984 no se muestra modelo familiar puesto que va contra las normas. Los sujetos aparecen aislados y exentos de libertad extirpando así su humanidad. La única lealtad posible es al Partido. “¿Cómo vas a tener un eslogan como el de -la libertad es una esclavitud- cuando el concepto de libertad no exista? Todo el clima de pensamiento será distinto. En realidad, no habrá pensamiento en el sentido en que ahora lo entendemos. La ortodoxia significa no pensar, no necesitar el pensamiento. Nuestra ortodoxia es la inconsciencia"

Los ritos de paso de los infantes son claros y conducen a un único camino. En este camino único se excluye el pensamiento autónomo y la lectura materializada en los libros como elemento diferenciador y distorsionador del orden para el buen funcionamiento de la macroestructura. Los personajes que acceden a ellos rompiendo la norma son castigados ya que constituyen un peligro social: torturados (Orwell), "liberados" o sucumben al 
suicidio como vía (Lowry y Huxley), exiliados (Bradbury), es decir, sufren. Leer impide ser felices porque llena de angustia. Los hombres empiezan a ser diferentes cuando deben ser iguales" (Bradbury, I993).

Para el sufrimiento la propia macro-estructura tiene sus sedantes, la química (contra el Ardor en Lowry, o la depresión con el soma en Huxley). Con ellos se suprimen los sentimientos “extraños”, utilizando una palabra de Jonás y se mantiene vivos (pero no humanos) a los individuos, ya que se elimina parte sustancial de su existencia.

Se controlan en las sociedades de ficción descritas las emociones y los pensamientos mediante vigilancia explícita (Gran Hermano -Orwell-, Altavoces -Lowry-) y el uso-desvirtualización-control lingüístico.

Hay una eliminación de la cara oculta de la luna: la muerte, el dolor, la duda o la capacidad de hacerse preguntas, es decir, del pensamiento; hay una supresión de lo diferente para uniformar literal y literariamente a la sociedad y curiosamente esta omisión de aspectos humanos que se repite en las cuatro novelas sólo subraya la carencia y necesidad de estos factores como propios del ser humano (la libertad, la posibilidad de equivocarnos en las elecciones tomadas, la valoración de los aspectos positivos al vislumbrar los negativos, llenando de sentido los hechos, los sentimientos, las vivencias, los pensamientos...la vida humana.) Quizá lo importante no es tanto mantenerse vivo sino mantenerse humano, dice Orwell.

Hago un llamamiento a que descubramos aquello que nos es realmente cercano y podemos utilizar para sopesar y reflexionar. A leer profundamente, no para creer, no para contradecir, sino para aprender a participar de esa naturaleza única que escribe y lee. A limpiarnos la mente de tópicos, no importa qué idealismo afirmen representar. Sólo se puede leer para iluminarse a uno mismo: no es posible encender la vela que ilumine a nadie más (Bloom, 2000: 27)

Veamos ahora más detenidamente algunos aspectos relevantes de la obra de Lowry ya que es la publicación más reciente y podemos considerarla actual. Analizaremos aspectos relacionados con la micro y macro estructura de esta comunidad e intentaremos responder a las preguntas ¿Podemos atisbar reflejo de la misma en la sociedad? ¿Es interesante o recomendable su lectura para adolescentes y jóvenes?

\section{I. La trama de The giver}

En esta sociedad que muestra la obra de Lowry, anualmente se celebra la ceremonia de los Doce donde cada niño al cumplir esta edad recibe del Comité de Ancianos la misión que desempeñará en su vida para satisfacer las necesidades de la Comunidad. Jonás y su familia esperan el rito anual con ilusión pero el protagonista de la novela de Lowry se enfrentará con una dura asignación: ser el Receptor de Memoria. Desde este momento tendrá acceso a información (recuperación de recuerdos buenos y malos de la historia de la humanidad) y libros. Esto le llenará de conocimiento y poder, pero también 
de dolor, soledad, dudas y preguntas sobre el funcionamiento de su comunidad. Será formado por el más honorable de los ancianos, el Dador, quien le ayudará a darse cuenta de los oscuros secretos que subyacen tras la frágil percepción de su mundo. Elegirá valientemente buscar el camino posible y huir llevándose consigo a un recién nacido que está condenado por sus iguales a la "liberación" (a la muerte). Caminar hacia otro lugar verdadero, con los colores de las cuatro estaciones sin exclusión posible, con todas las tristezas y todas las alegrías que la vida del hombre contiene en el elegir constante de posibilidades desde la conciencia. Caminar intentando llegar a un lugar más humano.

¿Lo conseguirá o su caminar le devolverá al punto de partida ya que no hay escapatoria salvo la liberación (muerte)? ¿Qué sucederá con la comunidad si su receptor de Recuerdos se marcha y el anciano Dador desaparece, ya que los recuerdos vuelven a los individuos que no están preparados para asumirlos (dado que desconocen la existencia de los mismos y no han sido formados para ello), cumpliendo una clara y única función social desde los doce años? ¿Lo conseguiremos nosotros, lectores, con y por ellos, por los personajes?

\subsection{Los personajes}

En lo que atañe a los personajes, hallamos a Jonás: protagonista de la historia. Seleccionado como el nuevo Receptor de Memoria en la ceremonia de los Doce por sus cualidades: inteligencia, integridad, valor "la formación que se te exige implica dolor... necesitarás un inmenso valor” (p. 86), sabiduría y capacidad de ver más; a Lily (Lily-laila): Hermana pequeña de Jonás. Tiene siete años. "Niño veintitrés -había leído el Nombrador en la Ceremonia de Imposición de Nombre y entrega del niño a la unidad familiar asignada- Lily... La gente aplaudió”. (p. 2I). Todavía tiene objeto sedante (seres imaginarios blandos para dormir. Peluche).

También encontramos al Padre de Jonás que cumple la función de Criador; a la Madre que ocupa un alto cargo en el Departamento de Justicia.

La madre de Jonás tenía más inteligencia que su padre, pero su padre tenía un carácter más tranquilo; se compensaban. Su unión, como todas las uniones, había sido sometida a un control de seguimiento por el Comité de Ancianos durante tres años antes de que pudieran solicitar hijos y, como siempre, había resultado bien (p. 68);

Y a Gabriel (Gabi). Es uno de los bebés que el padre de Jonás trata de ayudar en el centro de Crianza. Lo lleva a casa una temporada para fortalecerlo y conseguir que no sea liberado. Jonás le pasa alguno de los recuerdos que el Dador a su vez le ha dado. No puede permanecer en el núcleo familiar porque cada unidad familiar sólo puede tener dos hijos. Tiene los ojos claros, al igual que Jonás y el Dador “Además de ser una rareza, daban a quien los tenía un cierto aspecto de... ¿qué era? De profundidad, decidió” (p. 3i). "Jonás miró tímidamente a los ojos claros que reflejaban los suyos como un espejo" (p. IO2) Comparten la diferencia, rara en esta estructura extremadamente organizada donde los Nacidos que no cumplen las características requeridas según las Normas son libera- 
dos. "Sólo en dos casos la liberación no era castigo. Uno era la liberación de las personas muy ancianas... y la liberación de los Nacidos”. (p. I4); a-Asher y Fiona. Amigos de Jonás. Doces. Jonás sueña con Fiona y tiene su primer Ardor, desde ese momento es medicado. Asher será tras la ceremonia de Doce Subdirector de Recreación y Fiona Cuidadora de Viejos; al Comité de Ancianos. Encargados de observar la evolución de los niños de la comunidad para poder asignarles una misión a los doce años. "Al igual que la Unión de Cónyuges y la Imposición de Nombres y Colocación de los Nacidos, las Misiones eran escrupulosamente estudiadas por el Comité de Ancianos” (p. 68)

Por último, encontramos a El Dador de Recuerdos. Es el encargado de custodiar la memoria de la comunidad. Atesora recuerdos bellos y también dolorosos. Aconseja al comité de Ancianos si éstos requieren ayuda, y se queja de que le consulten poco. Tiene acceso a libros. "En realidad no soy tan viejo como aparento. Este trabajo me ha envejecido. Ahora parece como si ya me debiera faltar poco para la liberación... Necesito la fuerza que me queda para tu formación. Nos espera un trabajo duro y doloroso" (p.Io3). El Dador, al igual que Jonás, puede mentir, dato que los aleja del control al que está sometido el resto de la comunidad desde que comienzan el aprendizaje de la Precisión Lingüística a los tres años.

Y finalmente hallamos a ella. Diez años antes que a Jonás, se le asignó la misión de Receptor a Rosemary. Al recibir ciertos recuerdos dolorosos pidió al Presidente de Ancianos ser liberada (la muerte). Desde entonces a la comunidad se le dijo que había fracasado en su misión y que su nombre era impronunciable. Deshonor. Si le sucede algo al Receptor, los recuerdos que ha recibido y custodia no se pierden con él sino que vuelven a la gente. Esto supondría un desastre para la comunidad.

\subsection{La familia en The giver}

Como características relevantes referidas a la familia se nos presentan las siguientes: los padres no eligen el nombre de sus hijos. Los niños lo traen tras ser aceptada la solicitud para recibir un nuevo miembro en la unidad familiar y se conocen en la Ceremonia de Imposición de Nombres donde se le entrega el nuevo miembro. Cada unidad familiar sólo puede tener dos hijos que las Paridoras han dado a luz y los Criadores han cuidado hasta que son entregados. Hasta la Imposición de Nombre cada niño es llamado por su número original. Los padres utilizan el número cuando el hijo les irrita al tener un mal comportamiento.

Con la Unión de cónyuges se estudian las solicitudes de esposo y esposa. Estas solicitudes se estudian y si procede se aprueba y anuncia la Unión. "Era necesario que todos los factores -disposición, nivel de energía, inteligencia y gustos- se complementaran y armonizaran perfectamente" (p. 67)

El recuerdo preferido de El Dador es el del amor, que aparece asociado a la memoria de una habitación con una familia y los abuelos. “¿Lo recuerdas, Jonás? Sí -dijo. Tenía aquella sensación maravillosa que usted me dijo que era amor” (p. I88)

En la comunidad cuando llegan a la vejez abandonan la unidad familiar y marchan a la Casa de los Viejos hasta que son liberados. La familia por lo tanto, no contempla la figura de los abuelos. 
Además del control invisible pero sí audible del Consejo de Ancianos (la omnipresente voz de los altavoces) en las unidades familiares se hacen reuniones diarias donde todos sus miembros (reducido a cuatro máximo, por norma) cuentan su día a día y también sus sueños. La mentira no está permitida por lo que todos están informados de todo lo que sucede. El texto termina con una audición musical por parte de Jonás... ¿será la omnipresente voz de los altavoces? ¿Es así como son liberados? O... consigue su propósito de escapar de esa comunidad a la que ya no quiere regresar porque ha visto más allá de las sombras proyectadas en la caverna, que diría Platón? El receptor dirá, tras la lectura de la obra.

\subsection{Características de la comunidad}

La comunidad descrita en este libro destaca porque sus miembros creen que sólo existe la comunidad, el resto es Afuera. Tampoco conciben la temporalidad.

La última de las ceremonias es la del Doce. "A partir de los doce la edad no importa”... Lo importante es la preparación para la vida adulta y la formación que recibas para tu Misión”. (p. 26-27)

El mobiliario es igual en toda la comunidad: "práctico, duradero, claramente definida la función de cada mueble" (p. IOO). Igual sucede con los miembros de la comunidad una vez se les es asignada una función en la ceremonia del Doce. La asignación de obrero supone una misión de poco honor. Las paridoras, por ejemplo, son válidas para desempeñar esa función durante tres partos y luego son obreras el resto de sus días hasta que ingresan en la Casa de los Viejos. "La misión de paridora es de muy poco honor... ¿Es eso lo que tú quieres, Lily? ¿Tres años de holgazanería y luego trabajos físicos duros?” (p. 33). Existe por tanto, la jerarquía a la hora de asignar la misión.

No está permitido hacer preguntas personales o señalar alguna mínima diferencia entre los miembros de la comunidad. A Jonás, al recibir su hoja de obligaciones como Receptor de Memoria se le informa de que "puedes preguntar lo que quieras a cualquier ciudadano y te responderá” (p. 93)

Las profesiones se reparten a los doce años en función de la observación implacable y continua del Consejo de Ancianos.

Diferente al resto tiene la apostilla de inquietante. Esta apreciación la encontramos al referirse por ejemplo al color de ojos de Gabriel o Jonás. "En la comunidad se considera grosero señalar lo que un individuo tuviera de diferente o inquietante" (p. 3o)

Otra de las normas que encontramos es la prohibición de mencionar o comentar los éxitos propios. "Prohibido presumir, aunque fuera sin querer" (p. 39)

\section{$5 \cdot 5$. Elementos de control}

Como principal instrumento para controlar a la población se utiliza el término Precisión de lenguaje, es decir, control mediante el dominio lingüístico. 
La palabra Amor es una palabra muy generalizada, vacía de contenido que ya casi no se usa" ... "Nuestra comunidad no puede funcionar como es debido si no hablamos con precisión. ¿Sentís amor por mí? Esta es una pregunta insatisfactoria.- dijo Mamá. Podrías preguntar: ¿Estáis a gusto conmigo? La respuesta es sí -dijo su madre. O -sugirió su padre-: ¿Estáis orgullosos de lo que hago? Y la respuesta es un sí sin reservas. ¿Comprendes por qué es insatisfactorio emplear una palabra como Amor? (p. I7I)

La muerte es tratada en la novela con el término Liberación.

"La mala conducta le hacía a uno indigno de nombre" (p. 69)

"Desde su primer aprendizaje de la lengua, se le había enseñado que no había que mentir nunca. Era parte esencial de aprender a hablar con propiedad” (p. 96)

Unido al anterior ejemplo encontramos otro elemento de control en el seno familiar. A Jonás, al recibir las normas como Receptor de Memoria se le prohíbe contar nada relacionado con su formación. Se le prohíbe la medicación, narrar sueños y puede mentir. Todos estos elementos de control lo diferencian de la comunidad, al igual que al Dador.

El libro de normas indica el comportamiento adecuado de todos los individuos para la convivencia en la Comunidad: "Si no encajas puedes pedir que te manden Afuera y te liberen. Lo dice en las Normas ¿Cómo iba a haber alguien que no encajase? ... La comunidad estaba meticulosamente ordenada, las selecciones se hacían con todo cuidado" (p. 67)

El Comité de Ancianos está siempre vigilante y se comunica mediante altavoces. Todos los espacios están preparados para que su voz llegue a cualquier rincón. “Atención. Recordamos a todas las niñas menores de nueve que las cintas del pelo deben permanecer bien atadas en todo momento". (p. 34) "Atención. Recordamos que todo ardor debe ser notificado para su tratamiento". (p. 52)

El castigo está contemplado en las normas y asumido por la comunidad. La liberación de los individuos que no se adecuen al sistema es la muerte.

\section{6- Reflexiones que surgen a partir del análisis de contenidos de The giver. EI dador de recuerdos}

A la luz de lo evidente por los datos mostrados en la literatura, trataremos de responder a las dos preguntas planteadas: ¿Podemos atisbar reflejo de la misma en la sociedad?, ¿es interesante o recomendable como lectura para adolescentes y jóvenes?

Llegados a este punto afirmaremos que efectivamente, las novelas distópicas, The Giver entre ellas, surgen como respuesta a aspectos que acaecen en la sociedad, que preocupan a algunas personas y que representan ideas actuales y emociones como el miedo ante sucesos reales del mundo globalizado. Reflejan o manifiestan el temor ante lo extremado o radicalizado de actitudes reales. Estas actitudes reales, miedos, ideas, tienen un 
sistema de representación: la literatura. (Siguiendo el análisis del sistema Hegeliano para comprender el puente entre la idea del hombre y su representación mediante el arte).

The Giver nos pone alerta, para no olvidar que los extremos terminan tocándose y por tanto, siendo lo mismo. Conducen a un único camino que supondría la supresión de aspectos inherentes al ser humano. Nos subrayan con luces de neón que no hemos de olvidar la individualidad, la crítica constante, el cuestionamiento de lo que acaece dada su importancia y esencialidad. La creatividad, la unicidad, la capacidad de elección y la capacidad de vivir, entendiendo la vida por la existencia de su opuesto. Ser felices, entendiendo la felicidad como elemento indisociable de su contrario. Ser conscientes de la realidad entendiendo la misma gracias a las pistas esenciales que nos deja la ficción literaria... Son necesarios los opuestos porque conviven en la naturaleza humana. ¿Cómo armonizarlos? Esa es otra cuestión a la que cada uno debe dar respuesta.

Quizá la vida sea el margen entre contrarios (dolor-alegría, risa-llanto, sociedadindividuo...). Quizá entre la utopía y la distopía que muestra la literatura se encuentre el mundo: la síntesis, espejo cóncavo y convexo donde de soslayo quede reflejado el mundo, en unos lugares y momentos con más azúcar, en otros lugares y momentos históricos con más hiel.

Tal vez la literatura utópica y distópica clamen a los lectores que la síntesis es posible y nos ayude a preservar ciertos aspectos necesarios por humanos, para no caer en posturas extremas, radicales, ya que quizá nos conduzcan donde la ficción nos muestra, con las consecuencias que también enseña.

Sí, inevitablemente es recomendable e interesante la lectura de esta obra para adolescentes y jóvenes, para todo lector crítico que crea todavía que "el crimen mental es la muerte”. Para que cada vez haya más lectores totales que transformen la información en conocimiento y el conocimiento sepan aplicarlo en su vida, por la Vida en su sentido último.

Dice Lowry en su dedicatoria: “A los niños, en cuyas manos dejamos el futuro”. Compartimos nosotros su decir con ella en estas páginas.

\section{7- La necesidad del lector crítico para el avance positivo de las estructuras sociales. A través del espejo y lo que Alicia encontró allí}

“Todos los hombres tienden por naturaleza al saber” (p. 34). Así comenzó Aristóteles su Metafísica hace más de veintiún siglos. El conocimiento, igual que el lenguaje, son capacidades humanas que nos sirven para habitar en este espacio-tiempo al que llamamos vida. La distintas sociedades de las distintas épocas se han ocupado de transmitir conocimiento a los más jóvenes (familia y educación) para ampliar su mundo y también servir de motor al desarrollo de esas mismas estructuras. Es innegable que el sujeto desde el alfa desea conocer y una buena estructura social y familiar ha de favorecer esta necesidad natural. 
Desde la aparición de la escritura, la memoria y creatividad de la humanidad ha quedado reflejada en los diferentes soportes que han contribuido a preservar la historia y fomentar el pensamiento, dado que la literatura representa algunas ideas de los sujetos que viven en esas sociedades (Romero Tobar, I985).

Es innegable afirmar, tras estas páginas, que la lectura es punto nodal para el avance de las estructuras sociales y del individuo, también y sobre todo este tipo de literatura que requiere un lector total, crítico, para que la búsqueda de conocimiento sea el denominador común a todos los sujetos y no suceda lo que los extremos literal y literariamente muestran, es decir, el conocimiento como sinónimo de dolor, exilio, aislamiento, inexistencia... Por eso y contra eso es importante que textos como los analizados sean leídos, existan.

La educación es una cosa muy necesaria... pero la literatura es realmente imprescindible. (...) Si desapareciera la literatura no perderíamos un arte sino el alma. (...) Ante todo la literatura es cultura, es decir, promoción, reforzamiento y garantía de la vida en tanto humana... por medio de la ficción se asienta y crece el alma, y sin alma, de nada sirven conocimientos ni destrezas: miremos sin complacencia ni desesperación a nuestro alrededor. (Savater, I988: 8).

Eduard Punset (2OII) utiliza un ejemplo que nos servirá para exponer la necesidad urgente de la sociedad de preparar a las personas para la lectura crítica, de formar (sin uniformar) lectores capaces de llegar al sentido último del signo gráfico. Narra cómo una tribu indígena que otea el horizonte es incapaz de vislumbrar los barcos que colonizarán su territorio por el simple hecho de que en su mundo ni tan siquiera existía una palabra para nombrar las naves que habrían de conquistarlos. Miraban al horizonte y no veían nada. Sólo el chamán de la tribu se daba cuenta de que "algo" estaba sucediendo a lo lejos en el mar. Es importante, fundamental, preparar a niños, adolescentes, jóvenes para ver más allá, ampliar su mundo, dotarlos de lecturas que fomenten el conocimiento crítico del mundo, su base lingüística. Sentar las bases para una lectura comprensiva y útil para la vida.

"Creer en todo y no creer en nada son ideas opuestas que no conducen a nada" dice Agustín de Hipona. Nosotros creemos en la literatura, en la lectura crítica como camino, en el análisis y la reflexión autónoma porque "el crimen mental en la muerte" dice Orwell en la ficción. El crimen mental es la muerte, decimos nosotros aquí, en estas páginas reales. Cada individuo, forjado en su cultura y con acceso libre y capacidad de análisis total de las muestras de la misma (la literatura en particular y el arte en general) sabrá observar dónde, en la realidad actual, puede localizar (para asumir como estime oportuno), el crimen mental al que alude Orwell.

Ojalá surjan preguntas y dudas y ganas de leer los signos tras estas páginas, porque significará que no estamos tan lejos de ser lectores críticos. Significará que nos hemos visto reflejados en alguna letra, palabra, frase, y que podemos elegir una existencia 
auténticamente asumida como deseaba Simone de Beauvoir, con todos sus colores y todas sus sombras... una realidad auténticamente asumida, libre, donde cada uno elige. ¿Y quién puede elegir mejor? Tal vez aquellos que han vislumbrado o deseado vislumbrar un poco más allá de la línea horizontal de lo finito, aquellos que han analizado las manifestaciones culturales de los hombres en su afán por comprender el mundo, trascender el límite gracias al arte, ese espejo que es... la literatura. Literatura como reflejo del mundo y parte del mismo; todos los tonos, las melodías, las líneas y conociendo el cromatismo, analiza, interpreta, selecciona, asume, toma conciencia y actúa en consecuencia. Si es así, ninguna elección es mejor que otra, puesto que todas o muchas han sido contempladas. He aquí la singularidad de los sujetos, la libertad consciente. Lo deseable. Lo verdaderamente humano.

Como afirmara el profesor de la pipa sin humo, el amigo y maestro José López Martí: "La literatura no representa ni figura el mundo, sino que lo explicita; en última instancia es el mundo mismo".

"Y vosotros" (pregunta al lector Carroll al final de su obra A través del Espejo)" ¿de quién creéis que fue el sueño? (...) La vida, ¿no es acaso sólo un sueño?” De nuevo y siempre la paradoja o partos sucesivos de ideas en el viaje: la vida. Vida como mayéutica constante: el viaje.

Entrar en la madriguera del conejo, como Alicia, implica entrar en el mundo de lo onírico, de la ficción, pero de ahí hemos de salir fortalecidos, esclarecidos, a la realidad que se nos mostrará más clara (quizá no más buena, ni idílica, ni bella, sino real en sus múltiples tonalidades) y estaremos preparados para afrontarla mejor, dado que ésta es una de las características de todo viaje desde el caminar del prisionero que escapa de la caverna de Platón: Aprender a ver y vivir con la nueva mirada. A partir de aquí cada cual decide.

En la sociedad de la información y la comunicación tenemos todos los signos que nos deja la literatura, las interpretaciones de los signos, las teorías filosóficas, antropológicas, científicas al alcance de la mano, literalmente, pulsando un botón pero, ¿realmente queremos viajar underground como Alicia, es decir, transformar esa información en conocimiento útil para la vida autónoma, despertando amanecidos, (aunque el amanecer sea lluvioso)?, o ¿preferimos la pastilla azul que ofrece Morfeo a Neo (Matrix) y permanecer en la caverna (donde la lluvia si el amanecer fuera lluvioso, no nos alcanzaría)? "Si tomas la pastilla azul fin de la historia. Despertarás en tu cama y creerás lo que quieras creerte. Si tomas la roja, te quedarás en el País de las Maravillas y yo te enseñaré hasta dónde llega la madriguera de conejos”. Dice Morfeo a Neo en el film Matrix.

Sería interesante y necesario ofrecer lecturas que abiertamente piden la reacción del lector y fomentar al mismo tiempo un desarrollo de la lectura crítica en las aulas para poder conocer y afrontar mejor la vida y sus matices múltiples y cambiantes. Para lograr armonizar los términos en una dialéctica consciente y plena. 
Querer desmitificar la conciencia constituye la antinomia fundamental: porque sería un esfuerzo imaginario reducir al individuo humano a una cosa simple, inimaginable, perfectamente determinada, es decir, incapaz de imaginación y alienada a la esperanza. Pero la poesía como el mito es inalienable. La más humilde de las palabras, la más estricta comprensión del más estricto de los signos es mensajero, a su pesar, de una expresión que nimba siempre el sentido propio objetivo... Así pues, nosotros que acabamos de tener en cuenta la imaginación, pedimos modestamente que se sepa tener en cuenta a la cigarra junto al débil triunfo de la hormiga. Porque la verdadera libertad y la dignidad de la vocación ontológica de las personas sólo se apoya en la espontaneidad espiritual y la expresión creadora que constituye el campo de lo imaginario (Durand I98I: 405).

He aquí la necesidad de ofrecer materiales que incendien la mente de los jóvenes, futuro de lo real y realidad futura. La necesidad de formar lectores críticos que lleguen a conclusiones propias ayudados, por qué no, por la literatura.

Tienes catorce años y preguntas cosas para las que no tengo respuesta. Entre otras razones, porque nunca hay respuestas para todo (...)

De lo que sí estoy seguro es de que no hay mejor vacuna que el conocimiento. Me refiero a la cultura, en el sentido amplio y generoso del término: no soluciona casi nada, pero ayuda a comprender, a asumir, sin caer en el embrutecimiento o en la resignación. Con ello quiero sugerirte que leas, que viajes, y que mires (...)

Para conocerte, para comprender, lee.”(Pérez Reverte, 2OOO) 


\section{Referencias}

- Aristóteles (i995). Metafísica. Libro I. Madrid: Espasa Calpe.

- Bloom H. (2000). Cómo leery por qué. Barcelona: Anagrama.

- Bradbury R. (1993) [1953]. Fahrenheit 45ı. Barcelona: Ed. Plaza y Janés.

- Carroll, L. (2003) [1865]. Alicia en el País de las Maravillas. A Través del Espejo, Madrid: Cátedra.

- Delors, J. (I996). La educación o la utopía necesaria. En informe a la UNESCO de la Comisión Internacional sobre la educación para el siglo XXI, presidida por Jacques Delors. La Educación encierra un tesoro. Madrid: UNESCO /Santillana, pp. I3-36.

- Durand G. (I982). Las estructuras antropológicas de lo imaginario. Madrid: Taurus.

- Hegel G. W. F. (2007). Lecciones sobre estética. Madrid: Akal Arte/Estética.

- Huxley, A. (2005) [1932]. Un mundofeliz. Barcelona: Plaza y Janés.

- Lowry L. (1993). The Giver. Eldador de recuerdos. León: Everest.

- Millán J. A. (20OI). La lectura y la sociedad del conocimiento. Madrid: Federación de gremios de editores de España.

- Moore, A. (2005) [ig88]. V de Vendetta. Barcelona: Planeta.

- Orwell. G. (2009). [1948]. 1984. Barcelona: Destino.

- Pérez Reverte A. (200o). Carta a María en Patente de corso. XL Semanal, ig de noviembre.

- Punset, E. (2OII). Elviaje al poder de la mente. Barcelona: Destino.

- Quintero Gallego A. (1987). Madurez y comprensión lectora. Salamanca: Ed. Amarú.

- Romero Tobar L. (1985). La aventura deleer. Barcelona: Salvat.

- Savater, F. (I988). Lo que enseñan los cuentos en Cuadernos de Literatura Infantily Juvenil, I, 8-I2. 